\title{
B erichtigungen.
}

Band IX.

Seite 848 Zeile 10 von oben lies 224 statt 229 .

\section{Band X.}

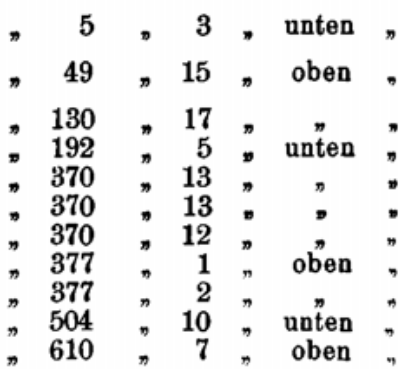

in der Formel im Zähler $+i$ statt $+h$.

$\Sigma \frac{u_{n}}{y^{n}}$ statt $\Sigma \frac{u^{n}}{y^{n}}$.

Primtalraekken statt Primtalrokken.

$2^{196}=10^{59} \ldots$ statt $2^{196}=10^{59}$.

Amorim statt Amarim.

- demonstração statt demonstracao.

- sobre a tóro statt solue a toro.

Determinação statt Determinacao.

da projecçã̃o statt du projeccas.

das statt dos.

T. C. Lewis statt J. C. Lewis.

\section{Band XI.}

$n 214 \quad 4 n$ oben $n \frac{1}{5^{2 n+1}}+\frac{1}{7^{2 n+1}}$ statt $\frac{1}{5^{2 n+2}}+\frac{1}{7^{2 n+2}}$.

n $217,14, n \quad, \quad \theta_{n}$ statt $\theta$.

$\eta 412,4, \quad, \quad\left(\begin{array}{c}2 n \\ n-1\end{array}\right)$ statt $\left(\begin{array}{c}n-1 \\ 2 n\end{array}\right)$.

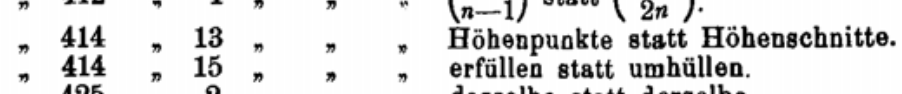

$\eta 425,2 n, \quad n$ dasselbe statt derselbe.

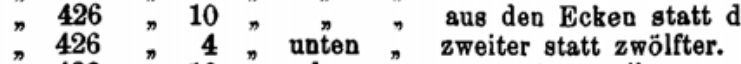

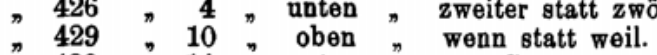

" 429 " 14 " unten " von $G$ statt von $P$.

” 434 " 7 "

" $440 " 15 "$ oben $"$ die Centralebene statt der Centralebene.

, 442

$\geqslant 446$

n 486

$\rightarrow 487$

2 2 unten

$\begin{array}{rrr}n & 16 & \text { oben } \\ & 2 & \end{array}$

n desselben statt derselben.

n einfache statt einfachste.

vier statt nean.

oben $"$ Rosanes statt Reje. 
